\begin{tabular}{|c|l|}
\hline Title & $\begin{array}{l}\text { Mechanistic study of asymmetric Michael addition of mal onates to enones catalyzed by a primary amino acid lithium } \\
\text { salt }\end{array}$ \\
\hline Author(s) & Yoshida, Masanori; Nagasawa, Y uki; Kubara, A mi; Hara, Shoji; Y amanaka, Masahiro \\
\hline Citation & $\begin{array}{l}\text { Tetrahedron, 69(47), 10003-10008 } \\
\text { https:/doi.org/10.1016/.tet.2013.09.066 }\end{array}$ \\
\hline Issue Date & 2013-11-25 \\
\hline Doc URL & http://hdl.handle.net/2115/57393 \\
\hline Type & article (author version) \\
\hline File Information & manuscript-myoshidatet0829-rev1-huscap.pdf \\
\hline
\end{tabular}

Instructions for use 


\title{
Mechanistic study of asymmetric Michael addition of malonates to enones catalyzed by a primary amino acid lithium salt
}

\author{
Masanori Yoshida a,b,*, Yuki Nagasawa ${ }^{\mathrm{c}}$, Ami Kubara ${ }^{\mathrm{b}}$, Shoji Hara ${ }^{\mathrm{a}, \mathrm{b}}$ and Masahiro Yamanaka, \\ ${ }^{a}$ Division of Chemical Process Engineering, Faculty of Engineering, Hokkaido University, Kita 13-jo Nishi 8, Kita-ku, Sapporo, Hokkaido 060-8628 Japan. \\ ${ }^{b}$ Molecular Chemistry and Engineering Course, Graduate School of Chemical Sciences and Engineering, Hokkaido University, Kita 13-jo Nishi 8, Kita-ku, \\ Sapporo, Hokkaido 060-8628 Japan. \\ ${ }^{c}$ Department of Chemistry, Faculty of Science, Rikkyo University, 3-34-1 Nishi-Ikebukuro, Toshima-ku, Tokyo 171-8501, Japan.
}

E-mail addresses: myoshida@eng.hokudai.ac.jp (M. Yoshida), myamanak@rikkyo.ac.jp (M. Yamanaka)

\section{ARTICLE INFO}

\section{ABSTRACT}

\section{Article history:}

Received

Received in revised form

Accepted

Available online

\section{Keywords:}

Organocatalysis

Asymmetric synthesis

Primary amino acid

Michael addition

DFT calculation

\begin{abstract}
A mechanistic study was carried out for the asymmetric Michael addition reaction of malonates to enones catalyzed by a primary amino acid lithium salt to elucidate the origin of the asymmetric induction. A primary $\beta$-amino acid salt catalyst, $O$-TBDPS $\beta$-homoserine lithium salt, exhibited much higher enantioselectivity than that achieved with the corresponding catalysts derived from $\alpha$ - and $\gamma$-amino acids for this reaction. Detailed studies of the transition states with DFT calculations revealed that the lithium cation and carboxylate group of the $\beta$ amino acid salt catalyst have important roles in achieving high enantioselectivity in the Michael addition reaction of malonates to enones.
\end{abstract}

2009 Elsevier Ltd. All rights reserved.

\section{Introduction}

Since the rediscovery of a simple secondary $\alpha$-amino acid, Lproline, as a high-potential catalyst in catalytic asymmetric synthesis, asymmetric organocatalysis has achieved explosive growth as a result of efforts to develop unique catalysts. ${ }^{1}$ Asymmetric Michael addition reaction of carbon nucleophiles to $\alpha, \beta$-unsaturated ketones or enals is one of the synthetic methodologies that received much benefit from the growth of organocatalysis, and it has become a powerful tool for the carbon-carbon bond formation reaction to create a carbon stereogenic center on the $\beta$-position of carbonyl groups. ${ }^{2}$ As pioneering works in this reaction with organocatalysis, a rubidium salt of L-proline and a chiral (2-pyrrolidyl)alkyl ammonium hydroxide were discovered as effective catalysts for the asymmetric Michael addition of malonates to enones by Yamaguchi $^{3}$ and Taguchi, ${ }^{4}$ respectively, in the early 1990s. Since Michael addition reaction of malonates to enones provides 1,5ketoesters, which are synthetically useful substrates, there is much interest in the development of new chiral organocatalysts for this reaction and elucidation of their reaction mechanisms. ${ }^{1,2,5}$

We recently reported that a primary $\beta$-amino acid salt, $O$ TBDPS $\beta$-homoserine lithium salt (1), was an effective catalyst for the Michael addition reaction of dimethyl malonate (2) to 2cyclohexen-1-one (3) and that the $\beta$-amino acid moiety was necessary for obtaining Michael adduct 4 with high enantioselectivity, since $\alpha$ - and $\gamma$-amino acid salt analogues 5 and 6 resulted in lower enantioselectivity than that from using the $\beta$ amino acid salt catalyst $\mathbf{1}$ (Scheme 1 ). ${ }^{6}$ After carrying out detailed optimization of the reaction conditions with $\beta$-amino acid salt catalyst $\mathbf{1}$, we succeeded in obtaining various $1,5-$ ketoesters in high yields (up to 92\%) with high
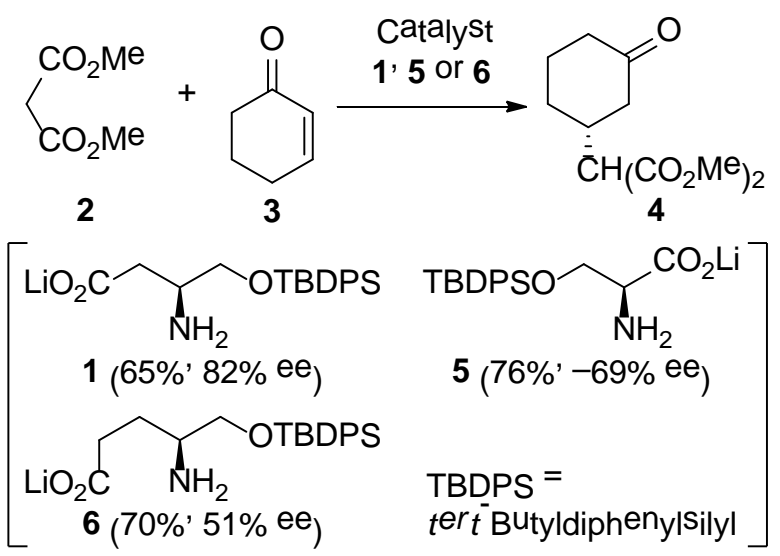

Scheme 1. Michael addition reaction of dimethyl malonate (2) to 2-cyclohexen-1-one (3) catalyzed by a primary amino acid lithium salt $(\mathbf{1}, \mathbf{5}$ and $\mathbf{6})$. Isolated yield and enantiomeric excess of the (R)enantiomer of Michael adduct $\mathbf{4}$ are shown in parentheses. 


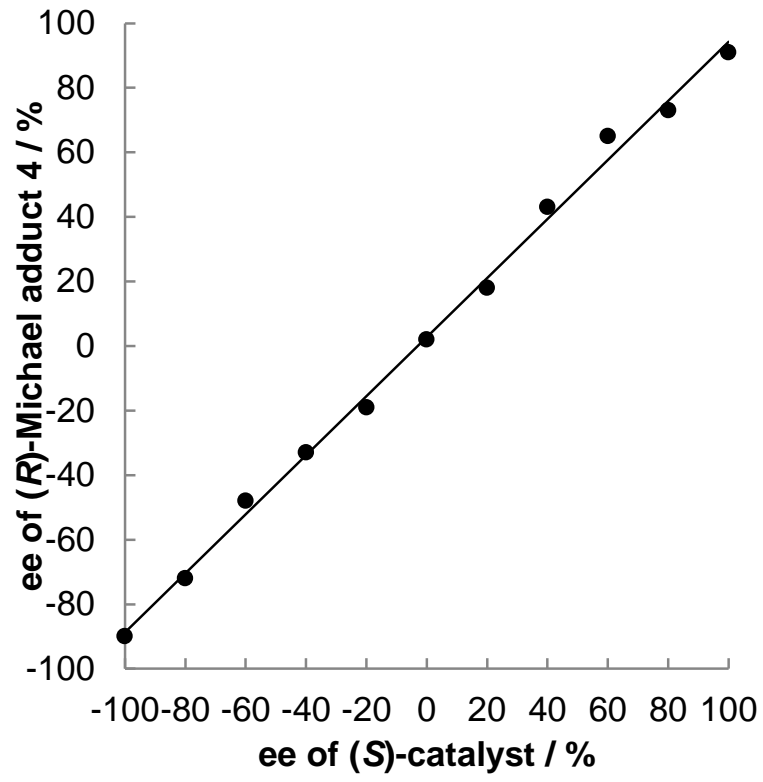

Figure 1. Linear relationship between enantiomeric excess of the Michael adduct $\mathbf{4}$ and $O$-TBDPS $\beta$-homoserine lithium salt catalyst. The Michael addition reaction was carried out with a mixed catalyst consisting of $\mathbf{1}$ and the original amino acid (1:3, $0.1 \mathrm{mmol}$ ), malonate $2(1 \mathrm{mmol})$, and enone $3(0.5 \mathrm{mmol})$ in $\mathrm{DMSO} /\left(\mathrm{CH}_{2} \mathrm{Cl}\right)_{2}(1: 2,0.5$ $\mathrm{mL}$ ) at $25{ }^{\circ} \mathrm{C}$ for $24 \mathrm{~h}$ according to our previous report. ${ }^{6 \mathrm{a}}$ Yields of 4 were ranged from 74 to $88 \%$.

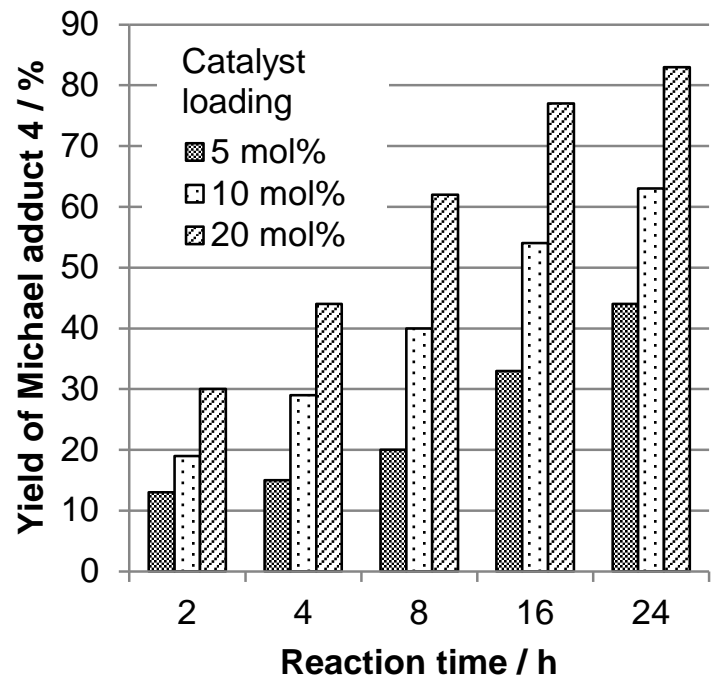

Figure 2. Effect of catalyst loading on the Michael addition reaction of malonate $\mathbf{2}$ to enone $\mathbf{3}$. The Michael addition reaction was carried out with a mixed catalyst consisting of $\mathbf{1}$ and the original amino acid (1:3), malonate 2 ( $1 \mathrm{mmol})$, and enone $3(0.5 \mathrm{mmol})$ in $\mathrm{DMSO} /\left(\mathrm{CH}_{2} \mathrm{Cl}\right)_{2}(1: 2,0.5 \mathrm{~mL})$ at $25^{\circ} \mathrm{C}$.

enantioselectivities (up to $97 \%$ ee); however, the function of the $\beta$-amino acid salt moiety in the Michael addition reaction to achieve high enantioselectivity remains elusive. Although several reports about successful organocatalysis using a $\beta$-amino acid catalyst have been published, there have been few mechanistic studies compared with studies on organocatalysis using an $\alpha$ amino acid catalyst. ${ }^{7}$ In this context, we carried out a mechanistic
Table 1. Solvent effect in the Michael addition of malonate $\mathbf{2}$ to enone $\mathbf{3}$ catalyzed by primary amino acid salt 1. ${ }^{a}$

\begin{tabular}{|c|c|c|c|}
\hline 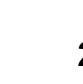 & cat & & 4 \\
\hline Entry & Solvent & $\begin{array}{l}\text { Yield } \\
(\%)^{b}\end{array}$ & $\begin{array}{l}\text { ee } \\
(\%)^{c}\end{array}$ \\
\hline 1 & DMSO & 61 & 59 \\
\hline 2 & $\mathrm{CH}_{2} \mathrm{Cl}_{2}$ & 28 & 60 \\
\hline 3 & $\left(\mathrm{CH}_{2} \mathrm{Cl}\right)_{2}$ & 30 & 56 \\
\hline 4 & $\mathrm{DMSO} / \mathrm{CH}_{2} \mathrm{Cl}_{2}(2: 1)$ & 52 & 81 \\
\hline 5 & DMSO/ $\mathrm{CH}_{2} \mathrm{Cl}_{2}(1: 1)$ & 51 & 87 \\
\hline 6 & $\mathrm{DMSO} / \mathrm{CH}_{2} \mathrm{Cl}_{2}(1: 2)$ & 49 & 88 \\
\hline 7 & $\mathrm{DMSO} /\left(\mathrm{CH}_{2} \mathrm{Cl}\right)_{2}(2: 1)$ & 42 & 85 \\
\hline 8 & $\mathrm{DMSO} /\left(\mathrm{CH}_{2} \mathrm{Cl}\right)_{2}(1: 1)$ & 42 & 87 \\
\hline 9 & $\mathrm{DMSO} /\left(\mathrm{CH}_{2} \mathrm{Cl}\right)_{2}(1: 2)$ & 43 & 90 \\
\hline
\end{tabular}

${ }^{a}$ The Michael addition reaction was carried out with catalyst 1 (0.05 mmol), malonate 2 (1 mmol) and enone 3 $(0.5 \mathrm{mmol})$ in a solvent $(1 \mathrm{~mL})$ at $25{ }^{\circ} \mathrm{C}$ for $24 \mathrm{~h} .{ }^{b}$ Isolated yield of 4 based on 3. ${ }^{c}$ Determined by chiral HPLC analysis.

study with DFT calculations to determine why the $\beta$-amino acid salt catalyst $\mathbf{1}$ is effective for obtaining 1,5-ketoesters with high enantioselectivity in the Michael addition reaction of malonates to enones and why the catalyst exhibits higher enantioselectivity than that of the $\alpha$ - and $\gamma$-amino acid salt catalysts $\mathbf{5}$ and $\mathbf{6}$.

\section{Results and discussion}

To verify a reliable chemical model, it is necessary to determine how many molecules of the catalyst participate in the transition state (TS). Two typical mechanistic studies were carried out as shown in Figures 1 and 2. ${ }^{8}$ First, we examined the Michael addition reaction of malonate 2 to enone 3 in the presence of a primary $\beta$-amino acid lithium salt catalyst $\mathbf{1}$ with various enantiomeric excesses that were prepared from $O$ TBDPS ( $S$ )- and (R)- $\beta$-homoserines. A good linear relationship was obtained between the enantiomeric excesses of Michael adduct $\mathbf{4}$ and catalyst $\mathbf{1}$ (Figure 1). We next studied the effects of catalyst loading on the Michael addition reaction. It was found that the reaction rates are roughly proportional to the concentration of the catalyst at each reaction time (Figure 2). These results indicate that a monomeric reactive species would participate in the TS of the present Michael addition reaction.

In our previous studies on a primary amino acid salt-catalyzed Michael addition of malonates to enones, ${ }^{6,9}$ the use of a mixed solvent consisting of a coordinative solvent (DMSO) and a low polar solvent $\left[\left(\mathrm{CH}_{2} \mathrm{Cl}\right)_{2}\right]$ was found to be essential to achieve high enantioselectivity (Table 1). The solvent effect indicates that DMSO would coordinate with the lithium cation to prevent aggregation of the reactive species during the course of the reaction. 


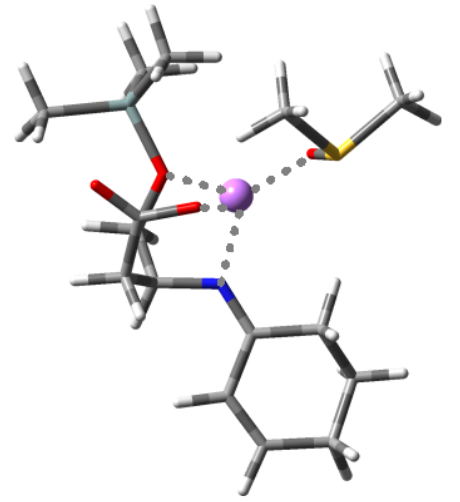

(Z) $-7(0.0 \mathrm{kcal} / \mathrm{mol})$

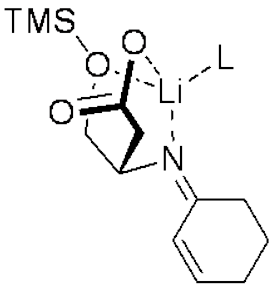

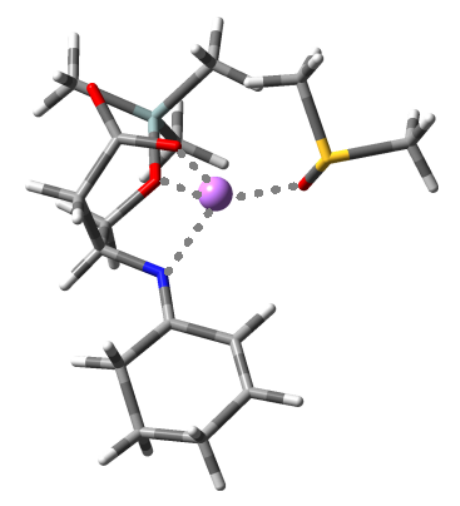

TMS

(E)-7 (+0.06 kcal $/ \mathrm{mol})$

Figure 3. Optimized structures of DMSO (L) coordinated (Z)- and (E)-7 (C, gray; O, red; N, blue; Li, purple; S, yellow; Si, sky-blue). Relative energies are shown in parentheses (B3LYP/6-311++G**//B3LYP/6-31G*).

(a) $\beta$ TS leading to major enantiomer $(L=D M S O)$

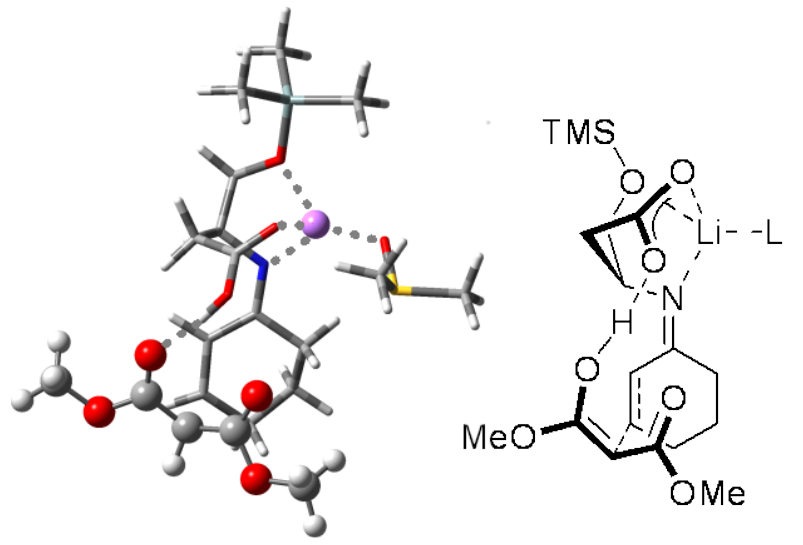

$\beta$ TSra $(0.0 \mathrm{kcal} / \mathrm{mol})$

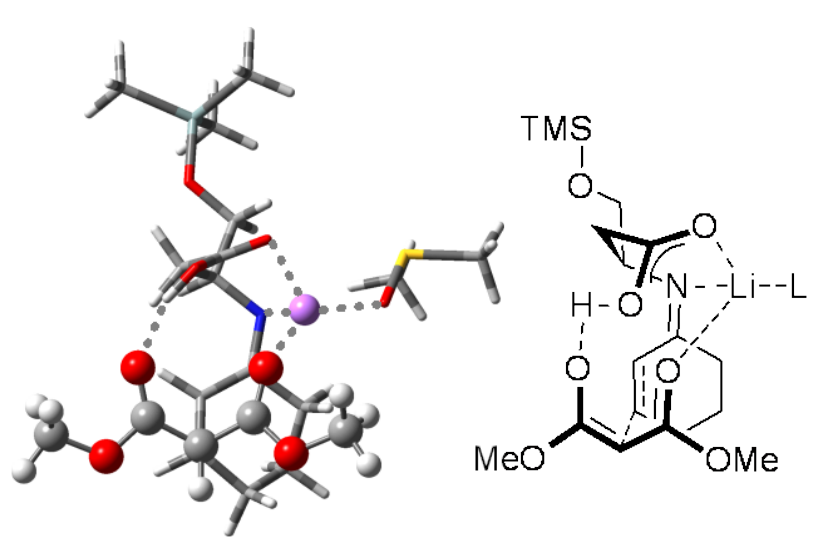

$\beta \mathrm{TS} r \mathrm{~b}(+7.9 \mathrm{kcal} / \mathrm{mol})$

(b) $\beta$ TS leading to minor enantiomer $(L=D M S O)$

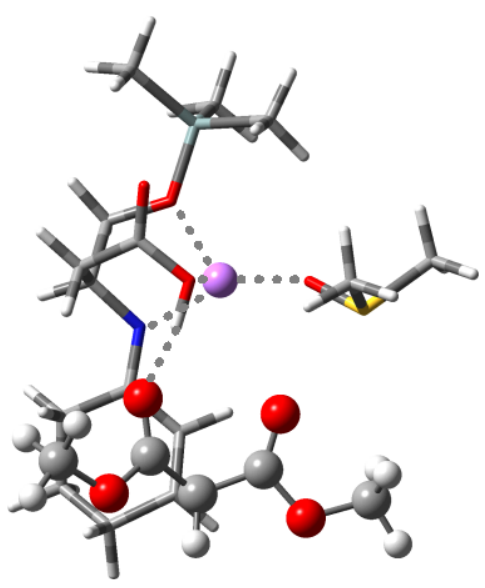

$\beta T S s a(+3.1 \mathrm{kcal} / \mathrm{mol})$

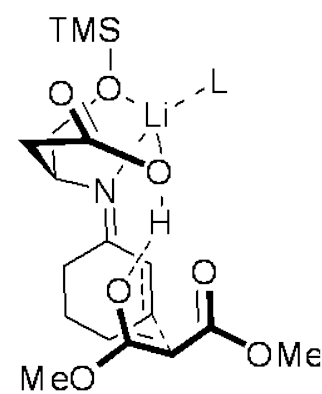

$\mathrm{MeO}$

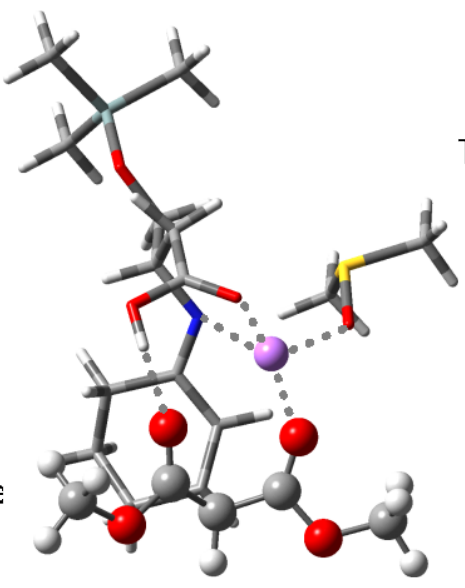

TMS

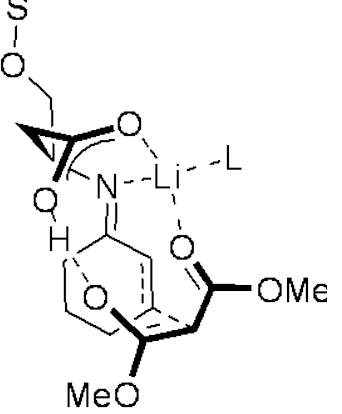

$\beta$ TSsb (+2.7 kcal $/ \mathrm{mol})$

Figure 4. Optimized structures of $\beta$ TS (C, gray; O, red; N, blue; Li, purple; S, yellow; Si, sky-blue; malonate 2, ball and stick model; imine 7, tube model). Relative energies are shown in parentheses (B3LYP/6-311++G**//B3LYP/6-311G*).

Based on these experimental mechanistic studies, DFT calculations $^{10}$ were carried out at the B3LYP/6$311+G(d, p) / / B 3 L Y P /-31 G(d)$ level using monomeric imine models, where DMSO coordinates with the lithium cation of the catalyst as an explicit solvent model and TMS is used instead of TBDPS to reduce computational cost (Figure 3). We have previously proposed that the reaction would proceed through the formation of imine intermediate $\mathbf{7}$ generated from enone $\mathbf{3}$ and catalyst 1, in which the Lewis acidic lithium cation of the catalyst would coordinate with the nitrogen atom of imine and the oxygen atom of the carboxylate group to form a stable six-membered ring structure. ${ }^{6 a, 9}$ DFT calculations exhibited noteworthy 
(a) $\alpha$ TS leading to major enantiomer $(L=$ DMSO)

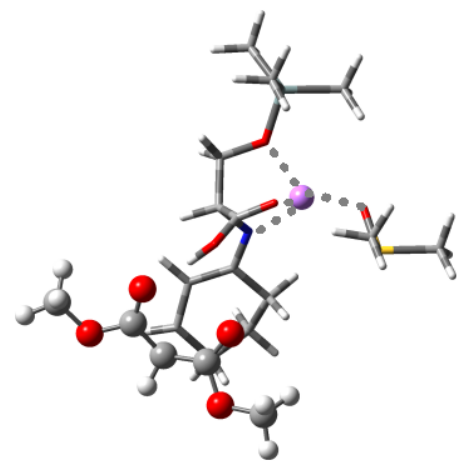

$\alpha \operatorname{TS} r a(0.0 \mathrm{kcal} / \mathrm{mol})$ (b) $\alpha \mathrm{TS}$ leading to minor enantiomer ( $L=\mathrm{DMSO})$

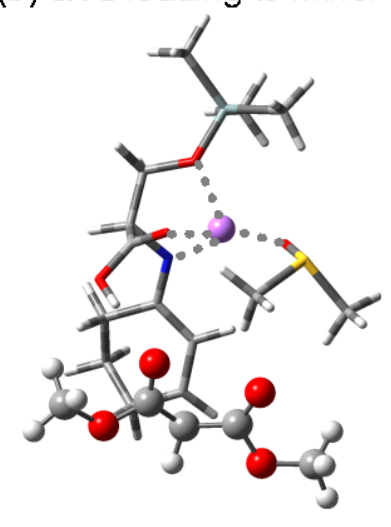

TMS

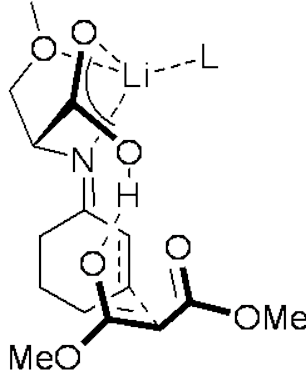

$\alpha$ TSsa $(+1.9 \mathrm{kcal} / \mathrm{mol})$

Figure 5. Optimized structures of $\alpha \mathrm{TS}$ with $(R)$-enantiomer of catalyst $\mathbf{5}$ (C, gray; O, red; N, blue; Li, purple; S, yellow; Si, sky-blue; malonate 2 , ball and stick model; imine, tube model). Relative energies are shown in parentheses (B3LYP/6-311++G**//B3LYP/6-311G*).

(a) $\gamma$ TS leading to major enantiomer $(L=D M S O)$

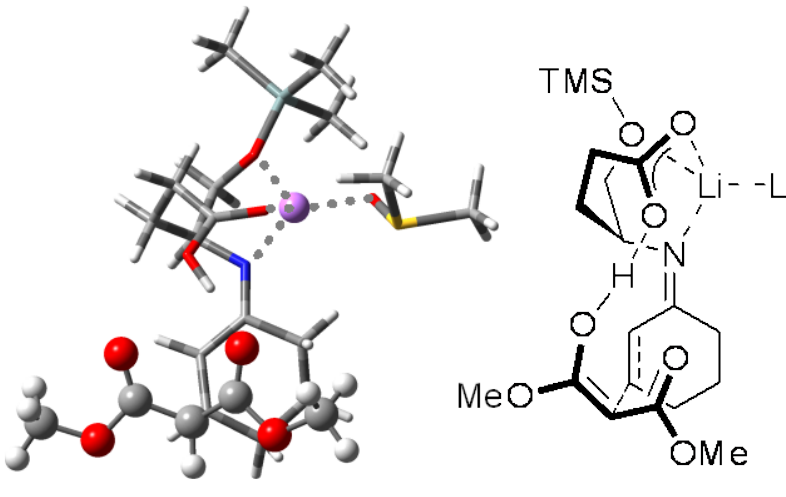

$\gamma^{T S} \mathrm{ra}(0.0 \mathrm{kcal} / \mathrm{mol})$

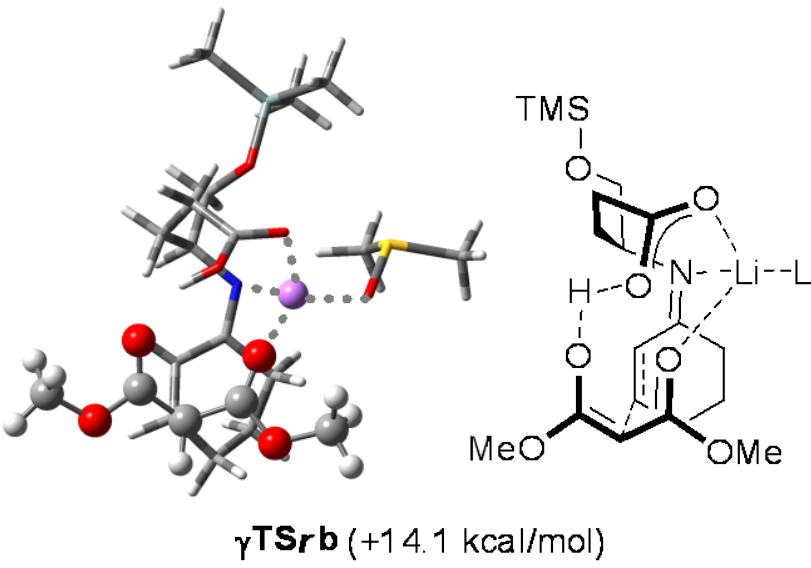

(b) $\gamma$ TS leading to minor enantiomer $(L=D M S O)$
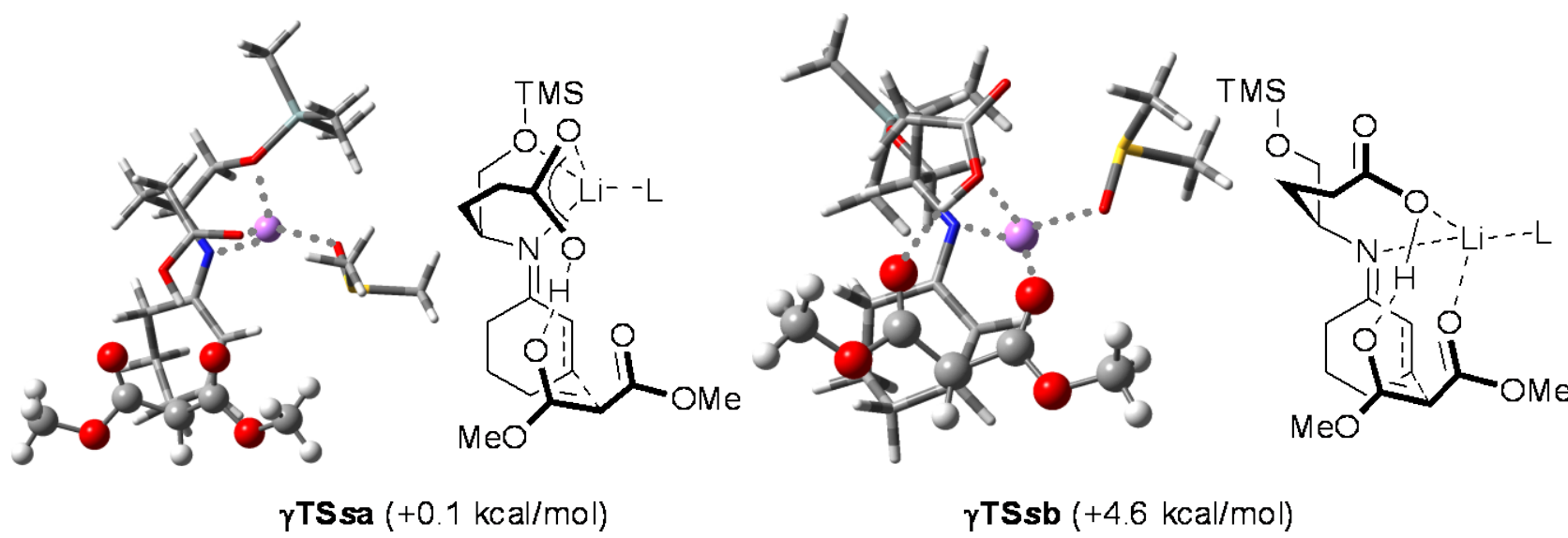

Figure 6. Optimized structures of $\gamma$ TS (C, gray; O, red; N, blue; Li, purple; S, yellow; Si, sky-blue; malonate 2, ball and stick model; imine, tube model). Relative energies are shown in parentheses (B3LYP/6-311++G**//B3LYP/6-311G*).

structural and energetic properties of imine 7. It was found that the lithium cation coordinates with not only the nitrogen atom of imine and the oxygen atom of the carboxylate group but also the oxygen atom of the siloxy group to form a stable bicyclic structure. Furthermore, it was found that there is little difference in energy between the geometric isomers, $(E)$ - and $(Z)-7$.

We then carried out DFT calculations for the TS of the present Michael addition reaction to reveal how the $\beta$-amino acid salt catalyst functions as an efficient asymmetric catalyst. As malonate 2 approaches imine 7 through hydrogen bonding with the carboxylate group, $(Z)$ - and (E)-7 lead to re-facial and sifacial attacking TSs, $\beta$ TSr and $\beta$ TSs, respectively (Figure 4). For these TSs, two types of lithium cation coordination models, a siloxy-coordinating model ( $\beta$ TSa) and an enolate-coordinating model ( $\beta$ TSb), were explored. In the re-facial attacking TSs, $\beta$ TSra is more stable than $\beta$ TSrb, since Lewis acidic lithium 
(a) $\beta T S$ leading to major enantiomer ( $L=D M S O)$

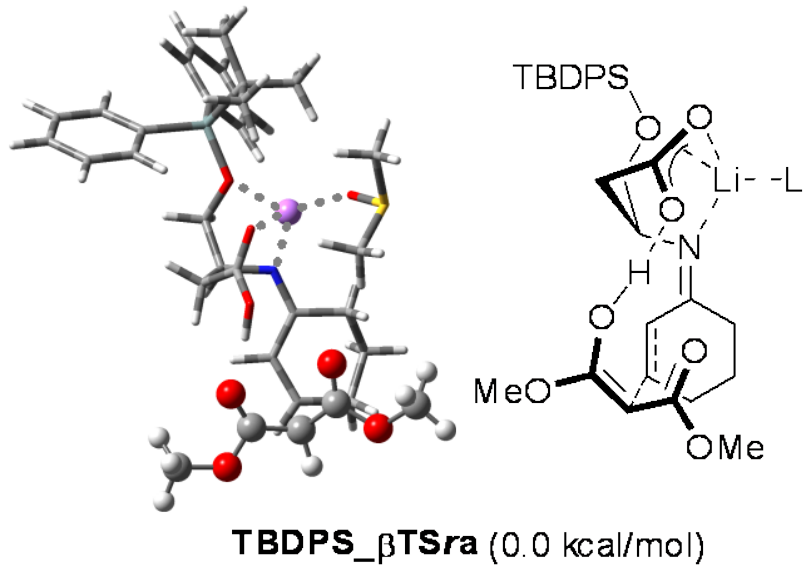

(b) $\beta$ TS leading to minor enantiomer $(L=D M S O)$

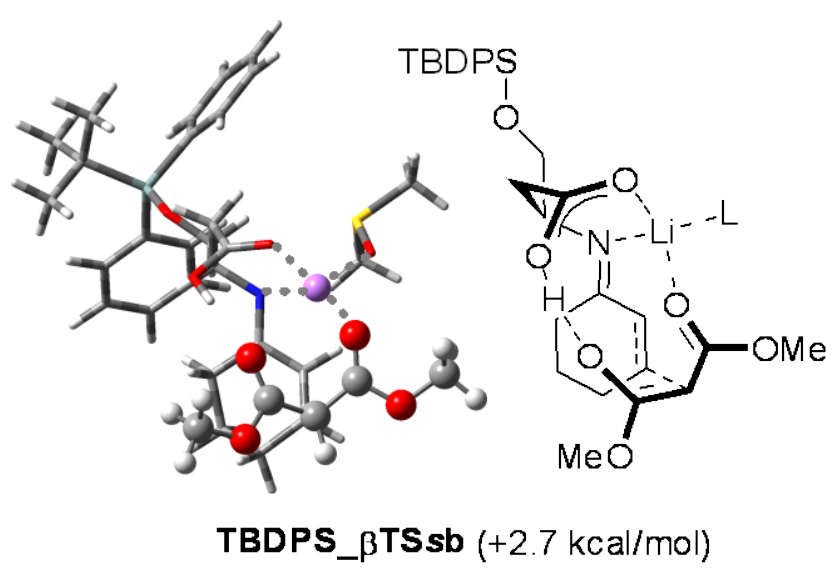

Figure 7. Optimized structures of TBDPS model of $\beta$ TS (C, gray; O, red; N, blue; Li, purple; S, yellow; Si, sky-blue; malonate 2, ball and stick model; imine, tube model). Relative energies are shown in parentheses (B3LYP/6-311++G**//B3LYP/6-311G*).

cation would favorably coordinate with the oxygen atom of the siloxy group, which has a more negative charge $(-0.914)$ than that of the carbonyl group of enolate $(-0.657)$. In addition, in $\beta$ TSrb, steric repulsion was observed between malonate 2 and methylene groups of the cyclohexene moiety (purple curves in Figure 4). Therefore, $\beta \mathbf{T S} r \mathbf{b}$ is higher in energy than $\beta$ TSra. As for the si-facial attacking TSs, in contrast, the enolatecoordinating model ( $\beta$ TSsb) is more stable than the siloxycoordinating model ( $\beta$ TSsa). Both of the oxygen atoms of the carboxylate group can be used for hydrogen bonding and coordination with the lithium cation in $\beta$ TSsb to provide resonance stabilization of the carboxylate group, whereas there is no such stabilization effect in $\beta$ TSsa. By comparison of the energy differences of these four diastereomeric transition structures, $\beta$ TSra and $\beta$ TSsb were determined as plausible TSs that give major and minor enantiomers of Michael adduct $\mathbf{4}$, respectively. In agreement with the experimental results, $\beta$ TSra leading to the major enantiomer of Michael adduct $\mathbf{4}$ is the energetically most favored. It was thus revealed that the carboxylate group of the $\beta$-amino acid salt catalyst has a role as a tether forming the stable bicyclic structure of imine 7 and grabbing the enolate of malonate $\mathbf{2}$ to bring it close to the prochiral center.

To obtain further detailed insight into the effect of tether length on stereochemical control, DFT calculations of TSs of the Michael addition reaction with $\alpha$ - and $\gamma$-amino acid salt catalysts ( $\alpha \mathbf{T S}$ and $\gamma \mathbf{T S}$ ) were also carried out (Figures 5 and 6). In $\alpha \mathbf{T S}$, the siloxy-coordinating models ( $\alpha \mathbf{T S a}$ ) were only optimized because the shorter tether length of the $\alpha$-amino acid moiety is not sufficient to form the enolate-coordinating models ( $\alpha \mathbf{T S b})$. The energy difference between $\alpha$ TSra and $\alpha$ TSsa (Figure 5, 1.9 $\mathrm{kcal} / \mathrm{mol}$ ) was smaller than that between $\beta \mathbf{T S} r a$ and $\beta \mathbf{T S s b}$ (Figure 4, $2.7 \mathrm{kcal} / \mathrm{mol}$ ). In a manner similar to the $\beta$-amino acid salt catalyst, the $\gamma$-amino acid salt catalyst has a long and flexible tether to form both siloxy-coordinating ( $\gamma$ TSa) and enolatecoordinating ( $\gamma \mathbf{T S b})$ models (Figure 6). In the re-facial attacking models, the structural and energy differences between $\gamma$ TSra and $\gamma \mathbf{T S}$ rb are similar to those obtained from the $\beta$-amino acid salt catalyst. A great difference in transition structures compared with the case of the $\beta$-amino acid salt catalyst was found in the sifacial attacking models ( $\gamma$ TSs) as follows: the siloxycoordinating model ( $\gamma$ TSsa) provides resonance stabilization of the carboxylate group, whereas there is no such stabilization effect in the enolate-coordinating model ( $\gamma$ TSsb). In contrast to $\beta$ TS, $\gamma$ TSsa is thus energetically more favored than $\gamma \mathbf{T S s b}$.
Therefore, there is a very small energy difference $(0.1 \mathrm{kcal} / \mathrm{mol})$ between $\gamma$ TSra and $\gamma$ TSsa. Those smaller energy differences between the re- and si-facial attacking models in both $\alpha \mathbf{T S}$ and $\gamma$ TS can support the experimental result that the Michael addition reaction with the $\alpha$ - and $\gamma$-amino acid salt catalysts 5 and $\mathbf{6}$ resulted in lower enantioselectivities.

Finally, we carried out DFT calculations of the TSs with a real system of $O$-TBDPS $\beta$-homoserine lithium salt $\mathbf{1}$ and found that a $r e$-facial attacking model (TBDPS_ $\beta$ TSra) is more stable than a si-facial attacking model (TBDPS_ß 3 TSsb) (Figure 7). It was thus confirmed that the results are in agreement with those obtained by using the $O$-TMS catalyst model.

\section{Conclusion}

By the present experimental and computational mechanistic studies, it was found that there is little energy difference between the two geometric isomers of an imine, which was generated from 2-cyclohexen-1-one and $O$-TBDPS $\beta$-homoserine lithium salt. DFT calculations of the TSs of conjugate addition of dimethyl malonate to this imine indicated that the lithium cation and the carboxylate group of the catalyst have important roles as an anchor to hold the stable bicyclic structure of the imine and as a tether to grab an enolate of malonate to bring it close to the prochiral center of the imine, respectively. By comparison with DFT calculations of the TSs with $\alpha$ - and $\gamma$-amino acid salts, it was revealed that $O$-TBDPS $\beta$-homoserine lithium salt has an appropriate length of the amino acid structure to achieve high enantioselectivity in the Michael addition reaction of malonates to enones.

\section{Experimental}

\subsection{General}

Solvents, dimethyl malonate (2) and 2-cyclohexen-1-one (3) were used after purification by distillation. $O$-TBDPS $\beta$ homoserine was prepared according to our previous report. ${ }^{6 a}{ }^{1} \mathrm{H}$ NMR (400 MHz) and ${ }^{13} \mathrm{C}$ NMR (100 MHz) spectra were recorded on a JEOL JNM-ECX400P. Chemical shifts, $\delta$ are referred to TMS $\left(\mathrm{CDCl}_{3}\right)$. Specific rotation was measured by a HORIBA SEPA-500. HPLC was carried out using a JASCO PU2089 Plus intelligent pump and a UV-2075 Plus UV detector.

4.2. Michael addition reaction of dimethyl malonate (2) to 2cyclohexen-1-one (3) catalyzed by O-TBDPS $\beta$-homoserine lithium salt (1) with various enantiomeric excesses (Figure 1). 


\subsubsection{Preparation of catalysts}

In a vial, ground $\mathrm{LiOH}$ mono hydrate (42 $\mathrm{mg}, 1 \mathrm{mmol}$ ) was added to a solution of $O$-TBDPS $(S)$ - $\beta$-homoserine (1.43 g, 4 $\mathrm{mmol})$ in $\mathrm{MeOH}(4 \mathrm{~mL})$ at $0{ }^{\circ} \mathrm{C}$. After stirring for overnight at room temperature, the reaction mixture was concentrated under reduced pressure. The obtained white solid was ground well and dried in vacuo to give a $1: 3$ mixture of $O$-TBDPS $(S)-\beta$ homoserine lithium salt $\mathbf{1}$ and the original amino acid. The corresponding $(R)$-catalyst was also synthesized in the same manner. The obtained $(S)$ - and $(R)$-catalysts were mixed in various proportions to give catalysts with various enantiomeric excesses.

\subsubsection{Michael addition reaction}

In a $7 \mathrm{~mL}$ vial, dimethyl malonate (2,132 $\mathrm{mg}, 1 \mathrm{mmol})$ was added to a solution of the catalyst obtained above (36 mg, 0.1 $\mathrm{mmol}$ ) and 2-cyclohexen-1-one (3, $48 \mathrm{mg}, 0.5 \mathrm{mmol})$ in $\mathrm{DMSO} /\left(\mathrm{CH}_{2} \mathrm{Cl}\right)_{2}(1: 2,0.5 \mathrm{~mL})$ at $25{ }^{\circ} \mathrm{C}$. After the reaction mixture was stirred for $24 \mathrm{~h}$ at $25{ }^{\circ} \mathrm{C}$, sat. aq. $\mathrm{NaCl}(1 \mathrm{~mL})$ was added to the vial and extracted with $\mathrm{Et}_{2} \mathrm{O}(1.5 \mathrm{~mL} \times 4)$. The combined organic phase was dried over $\mathrm{MgSO}_{4}$, filtered and concentrated under reduced pressure. 3[Bis(methoxycarbonyl)methyl]cyclohexanone (4) was isolated by column chromatography (silica gel, hexane/ $\mathrm{Et}_{2} \mathrm{O} 1: 1$ ) as oil. The enantioselectivity was determined by HPLC analysis [Daicel CHIRALPAK AS-H, 40\% isopropanol/hexane, $0.7 \mathrm{~mL} / \mathrm{min}, 218$ $\mathrm{nm}$; $\operatorname{tr}($ major $)=32.3 \mathrm{~min}, \operatorname{tr}($ minor $)=34.9 \mathrm{~min}]$. The absolute configuration was determined by comparison of the specific rotation with that of our previous report. ${ }^{6 a}[\alpha]^{26.0}{ }_{589}=+8.9^{\circ}(\mathrm{c}=$ $1.0, \mathrm{CHCl}_{3}, 91 \%$ ee); $\delta_{\mathrm{H}}\left(\mathrm{CDCl}_{3}\right)$ 1.45-1.55 (1H, m), 1.63-1.75 (1H, m), 1.91-1.98 (1H, m), 2.04-2.12 (1H, m), 2.23-2.31 (2H, m), 2.38-2.46 (2H, m), 2.50-2.59 (1H, m), $3.35(1 \mathrm{H}, \mathrm{d}, J 7.9 \mathrm{~Hz})$, $3.75(3 \mathrm{H}, \mathrm{s}), 3.76(3 \mathrm{H}, \mathrm{s}) ; \delta_{\mathrm{C}}\left(\mathrm{CDCl}_{3}\right)$ 24.0, 28.3, 37.6, 40.5, 44.6, 52.07, 52.09, 56.1, 167.7, 167.8, 209.0.

4.3. Effect of catalyst loading on the Michael addition reaction of dimethyl malonate (2) to 2-cyclohexen-1-one (3) (Figure 2).

Michael addition reactions were carried out in the same manner as shown in 4.2.2. but with various catalyst loading of an enantiopure 1:3 mixed catalyst consisting of $\mathbf{1}$ and the original amino acid (5 mol\%: $9 \mathrm{mg}, 0.025 \mathrm{mmol}, 10 \mathrm{~mol} \%$ : $18 \mathrm{mg}, 0.05$ mmol, 20 mol\%: $36 \mathrm{mg}, 0.1 \mathrm{mmol})$. Reactions were carried out for 2, 4, 8, 16 or $24 \mathrm{~h}$ and stopped to isolate Michael adduct 4 .

\section{Acknowledgement}

This work was supported by a Grant-in-Aid for Scientific Research on Innovative Areas "Advanced Molecular Transformations by Organocatalysts" from The Ministry of Education, Culture, Sports, Science and Technology, Japan (KAKENHI No. 24105501).

\section{Supplementary data}

Supplementary data associated with this article (molecular geometries and energies obtained by DFT calculations) can be found in the online version.

\section{References and notes}

1. Reviews and a book on organocatalysis: (a) MacMillan, D. W. C. Nature 2008, 455, 304; (b) Pellissier, H. Tetrahedron 2007, 63, 9267; (c) Dalko, P. I.; Moisan, L. Angew. Chem., Int. Ed. 2004, 43, 5138; (d) Houk, K. N.; List, B. Acc. Chem. Res. 2004, 37, 487; (e) Berkessel, A.; Gröger, H. Asymmetric Organocatalysis: From Biomimetic Concepts to Applications in Asymmetric Synthesis, Wiley-VCH, Weinheim, Germany, 2005.
2. Selected reviews on organocatalytic asymmetric Michael addition: (a) Dalpozzo, R.; Bartoli, G.; Bencivenni, G. Symmetry 2011, 3, 84; (b) Tsogoeva, S. B. Eur. J. Org. Chem. 2007, 1701; (c) Almaşi, D.; Alonso, D. A.; Nájera, C. Tetrahedron: Asymmetry 2007, 18, 299; (d) Berner, O. M.; Tedeschi, L.; Enders, D. Eur. J. Org. Chem. 2002, 1877.

3. Yamaguchi, M.; Shiraishi, T.; Hirama, M. J. Org. Chem. 1996, 61, 3520 and references cited therein.

4. Kawara, A.; Taguchi, T. Tetrahedron Lett. 1994, 35, 8805.

5. Organocatalytic Michael addition of malonates published recently: (a) Kim, J.-H.; Park, E.-J.; Lee, H-J.; Ho, X.-H.; Yoon, H.-S.; Kim, P.; Yun, H.; Jang, H.-Y. Eur. J. Org. Chem. 2013, 4337; (b) Świderek, K.; Pabis, A.; Moliner, V. Org. Biomol. Chem. 2012, 10, 5598; (c) Dudziński, K. Pakulska, A. M.; Kwiatkowski, P. Org. Lett. 2012, 14, 4222; (d) Moritaka, M.; Miyamae, N.; Nakano, K.; Ichikawa, Y.; Kotsuki, H. Synlett 2012, 23, 2554; (e) Ghosh, S. K.; Dhungana, K.; Headley, A. D.; Ni, B. Org. Biomol. Chem. 2012, 10, 8322; (f) Mase, N.; Fukasawa, M.; Kitagawa, N.; Shibagaki, F.; Noshiro, N.; Takabe, K. Synlett. 2010, 15, 2340; (g) Fleischer, I.; Pfaltz, A. Chem. Eur. J. 2010, 16, 95; (h) Procopio, A.; Nino, A. D.; Nardi, M.; Oliverio, M.; Paonessa, R.; Pasceri, R.; Synlett. 2010, 12, 1849; (i) Maltsev, O. V.; Kucherenko, A. S.; Zlotin, S. G. Eur. J. Org. Chem. 2009, 5134; (j) Riguet, E. Tetrahedron Lett. 2009, 50, 4283; (k) Yang, Y.-Q.; Zhao, G. Chem. Eur. J. 2008, 14, 10888; (l) Wascholowski, V.; Knudsen, K. R.; Mitchell, C. E. T.; Ley, S. V. Chem. Eur. J. 2008, 14, 6155; (m) Wang, Y.; Li, P.; Liang, X.; Ye, J. Adv. Synth. Catal. 2008, 350, 1383; (n) Ma, A.; Zhu, S.; Ma, D. Tetrahedron Lett. 2008, 49, 3075.

6. (a) Yoshida, M.; Narita, M.; Hara, S. J. Org. Chem. 2011, 76, 8513; (b) Yoshida, M.; Kubara, A.; Hara, S. Chem. Lett. 2013, 42, 180 .

7. (a) Kokotos, C. G. Org. Lett. 2013, 15, 2406; (b) Yang, H.; Wong, M. W. J. Org. Chem. 2011, 76, 7399; (c) Armstrong, A.; Bhonoah, Y.; White, A. J. P. J. Org. Chem. 2009, 14, 5041; (d) Zhang, H.; Mitsumori, S.; Utsumi, N.; Imai, M.; Garcia-Delgado, N.; Mifsud, M.; Albertshofer, K.; Cheong, P. H.-Y.; Houk, K. N.; Tanaka, F.; Barbas, III, C. F. J. Am. Chem. Soc. 2008, 130, 875; (e) Dziedzic, P.; Córdova, A. Tetrahedron: Asymmetry 2007, 18, 1033; (f) Davies, S. G.; Russell, A. J.; Sheppard, R. L.; Smith, A. D.; Thomson, J. E. Org. Biomol. Chem. 2007, 5, 3190; (g) Córdova, A.; Zou, W.; Dziedzic, P.; Ibrahem, I.; Reyes, E.; Xu, Y. Chem. Eur. J. 2006, 12, 5383; (h) Limbach, M. Tetrahedron Lett. 2006, 47, 3843; (i) Davies, S. G.; Shepperd, R. L.; Smith, A. D.; Thomson, J. E. Chem. Commun. 2005, 3802; (j) Buchschacher, P.; Cassal, J.-M.; Fürst, A.; Meier, W. Helv. Chim. Acta. 1977, 60, 2747.

8. (a) Xu, X.-Y.; Tang, Z.; Wang, Y.-Z.; Luo, S.-W.; Cun, L.-F.; Gong, L.-Z. J. Org. Chem. 2007, 72, 9905; (b) Blackmond, D. G. Angew. Chem. Int. Ed. 2005, 44, 4302; (c) Mathew, S. P.; Iwamura, H.; Blackmond, D. G. Angew. Chem. Int. Ed. 2004, 43, 3317; (d) Schmidt, B.; Seebach, D. Angew. Chem. Int. Ed. Engl. 1991, 30, 1321; (e) Puchot, C.; Samuel, O.; Dunach, E.; Zhao, S.; Agami, C.; Kagan, H. B. J. Am. Chem. Soc. 1986, 108, 2353; (f) Duangdee, N.; Harnying, W.; Rulli, G.; Neudörfl, J.-M.; Gröger, H.; Berkessel, A. J. Am. Chem. Soc. 2012, 134, 11196; (g) Klussmann, M.; Iwamura, H.; Mathew, S. P.; Wells Jr, D. H.; Pandya, U.; Armstrong, A.; Blackmond, D. G. Nature 2006, 441, 621.

9. Yoshida, M.; Narita, M.; Hirama, K.; Hara, S. Tetrahedron Lett. 2009, 50, 7297.

10. All DFT calculations were performed with the Gaussian 09 package: Gaussian 09, Revision B.01, Frisch, M. J.; Trucks, G. W.; Schlegel, H. B.; Scuseria, G. E.; Robb, M. A.; Cheeseman, J. R.; Scalmani, G.; Barone, V.; Mennucci, B.; Petersson, G. A.; Nakatsuji, H.; Caricato, M.; Li, X.; Hratchian, H. P.; Izmaylov, A. F.; Bloino, J.; Zheng, G.; Sonnenberg, J. L.; Hada, M.; Ehara, M.; Toyota, K.; Fukuda, R.; Hasegawa, J.; Ishida, M.; Nakajima, T.; Honda, Y.; Kitao, O.; Nakai, H.; Vreven, T.; Montgomery, Jr., J. A.; Peralta, J. E.; Ogliaro, F.; Bearpark, M.; Heyd, J. J.; Brothers, E.; Kudin, K. N.; Staroverov, V. N.; Kobayashi, R.; Normand, J.; Raghavachari, K.; Rendell, A.; Burant, J. C.; Iyengar, S. S.; Tomasi, J.; Cossi, M.; Rega, N.; Millam, J. M.; Klene, M.; Knox, J. E.; Cross, J. B.; Bakken, V.; Adamo, C.; Jaramillo, J.; Gomperts, R.; Stratmann, R. E.; Yazyev, O.; Austin, A. J.; Cammi, R.; Pomelli, C.; Ochterski, J. W.; Martin, R. L.; Morokuma, K.; Zakrzewski, V. G.; Voth, G. A.; Salvador, P.; Dannenberg, J. J.; Dapprich, S.; Daniels, A. D.; Farkas, Ö.; Foresman, J. B.; Ortiz, J. 
V.; Cioslowski, J.; Fox, D. J. Gaussian, Inc., Wallingford CT,

2009. 